\title{
Incidence of Symptomatic Vertebral Fracture with High- dose Glucocorticoid Treatment in the Chiba-Shimoshizu Rheumatic Cohort between 1986 and 2006
}

\author{
TAKAO SUGIYAMA*,***, ICHIRO TATSUNO ${ }^{* * * * * *}$, SAWAKO SUZUKI**,***, TOMOHIKO YOSHIDA**,***, \\ TOMOAKI TANAKA ${ }^{* *, * * *}$, MAKOTO SUEISHI ${ }^{* *, * * *}$ AND YASUSHI SAITO**,***
}

${ }^{*}$ Department of Rheumatology, National Hospital Organization Shimoshizu National Hospital, Chiba, Japan

${ }^{* *}$ Department of Clinical Endocrinology and Metabolism, Chiba University Hospital, Chiba, Japan

***Department of Clinical Cell Biology, Chiba University Graduate School of Medicine, Chiba, Japan

\begin{abstract}
We investigated the incidence of symptomatic vertebral fracture in patients who required long-term high-dose glucocorticoid (GC) treatment. The patients with collagen vascular diseases (aged 18 years or older) were registered to Chiba-Shimoshizu Rheumatic Cohort from 1986 to 2006. The study included the patients who were newly treated with the initial dose more than $20 \mathrm{mg}$ prednisolone equivalent per day at least for more than 6 months. Among 700 patients (female/ male: 539/161, mean age: 46.7 years, mean initial GC dose: $39.9 \mathrm{mg} /$ day), 167 patients (23.8\%) had at least one symptomatic vertebral fracture. Age and daily GC dose were significantly higher in the symptomatic fracture group than the no symptomatic fracture group. Cox regression model demonstrated that the relative risk for symptomatic vertebral fracture is independently higher in female patients, and in patients with initial higher age, and in those patients with initial higher GC dose and GC dose-increase, but lower with cumulative higher GC dose. High-dose GC treatment causes significantly high prevalence of symptomatic vertebral fracture in patients with collagen vascular disease. Age, female, higher initial $\mathrm{GC}$ dose and GC dose-increase are the risk factors for the symptomatic vertebral fracture in those patients.
\end{abstract}

Key words: Symptomatic vertebral fracture, Osteoporosis, Glucocorticoid, Collagen vascular disease

(Endocrine Journal 56: 591-599, 2009)

GLUCOCORTICOID (GC) -induced osteoporosis was first described by Cushing over 70 years ago, in which patients with excess endogenous GC was reported to develop bone fractures in Cushing's disease [1]. In the past decades, GC-induced osteoporosis and bone fractures have drawn attention, since synthetic GCs have been widely used in patients with autoimmune, pulmonary and gastrointestinal diseases, as well as in patients with organ transplants and neoplas-

Received Nov. 5, 2008; Accepted Mar. 13, 2009 as K08E-318 Released online in J-STAGE as advance publication Apr. 7, 2009 Correspondence to: Ichiro TATSUNO M.D., Ph.D., Department of Clinical Cell Biology, Chiba University Graduate School of Medicine, 1-8-1 Inohana, Chuo-ku, Chiba, 260-8670, Japan. E-mail: ichiro-tatsuno@faculty.chiba-u.jp

Abbreviations: CSRC, Chiba-Shimoshizu Rheumatic Cohort; GC, glucocorticoid; PSL, prednisolone tic diseases [1-8].

Collagen vascular diseases such as rheumatoid arthritis, systemic lupus erythematosus, Sjogren's syndrome, polymyositis/dermatomyositis, systemic sclerosis, and granulomatous vasculitic conditions exemplified by Wegener's granulomatosis are associated with immune dysregulation. They are chronic and sometimes involve multiple organs, thus occasionally life-threatening. To control disease activity, an immunosuppressive regimen with long-term and high-dose GC is necessary, but the treatment causes high incidence of osteoporosis [9-15].

In the present study, we investigated the risk factors of symptomatic vertebral fracture implicated in longterm use of high-dose GC in patients with collagen vascular diseases, analyzing a cohort at Shimoshizu National Hospital in Japan between 1986 and 2006. 


\section{Subjects and Methods}

\section{Subjects}

A total of 2631 patients was registered in the Chiba-Shimoshizu Rheumatic Cohort (CSRC) in the Department of Rheumatology of a highly specialized rheumatic center, Shimoshizu National Hospital (Chiba, Japan), between 1986 and 2006. These patients were mostly referred to our center for treatment of collagen vascular diseases involving multiple organs. All patients were diagnosed as having collagen vascular diseases such as systemic lupus erythematosus, Sjogren's syndrome, polymyositis/dermatomyositis, rheumatoid arthritis, systemic sclerosis, or the granulomatous vasculitic conditions exemplified by Wegener's granulomatosis. Among the patients, those (aged 18 years or older) who were newly treated with high-dose GC were included in the study. They were treated with an initial dose of $20 \mathrm{mg}$ or higher prednisolone (PSL) equivalent per day for at least 6 months without prior prophylactic treatment with bisphosphonate, hormone replacement therapy, or selective estrogen receptor modulator to prevent bone loss.

\section{Study design}

This was a 20 -year observational study in patients receiving high-dose GC therapy. Study subjects were generally followed up every one or two months. The follow-up period for each patient started with the initial administration of GC. Study subjects were monitored regarding gender, age, body weight, height, and clinical characteristics such as underlying disease, initial smoking, and initial alcohol use. Body mass index (BMI) was also calculated. We defined a GC doseincrease as the re-introduction of more than $20 \mathrm{mg}$ of GC per day (PSL equivalent) due to increased disease activity in patients whose doses were once tapered to less than $20 \mathrm{mg}$ of GC per day. In the fracture patients, the daily dose of PSL (mg/day) and the cumulative dose of PSL (g) were calculated from the data until fracture. This study was approved by the Ethics Committee of Shimoshizu National Hospital. The informed consent was waived.

\section{Symptomatic vertebral fracture}

A symptomatic vertebral fracture was defined as vertebral deformity that was confirmed by physical examination and spine $\mathrm{x}$-ray in patients with sudden severe backache. Lateral thoracolumbar radiograms of the spine were graded independently by a radiologist. Vertebral deformity was semi-quantitatively assessed by a method similar to that described by Genant et al. [16], and deformity was positively confirmed if there was more than a $20 \%$ reduction in anterior, middle or posterior vertebral height.

\section{Statistical analysis}

Data were expressed as means \pm SD. Potential risk factors for symptomatic vertebral fracture (age, gender, underlying disease, cumulative GC dose, mean daily GC dose, GS pulse therapy, numbers of GC dose-increase, smoking, and alcohol use) were first assessed in a univariate analysis. Differences in baseline characteristics were evaluated between two groups of patients by chi-square test and univariate analysis was performed with Student's t-test.

The no symptomatic vertebral fracture ratios were compared between the groups (smoking vs. no smoking, alcohol use vs. no alcohol used, and the groups with and without dose-increase) with the Kaplan Meier method and evaluated with log-rank test. Difference with $p$ value $<0.05$ was considered to be statistically significant.

The hazard ratio of symptomatic vertebral fracture was estimated for each risk factor with Cox regression model with $95 \%$ confidence interval. The ratios were adjusted for gender, BMI, initial age, smoking, alcohol use, initial GC dose, cumulative dose of GC, GC pulse therapy and number of GC dose-increase. All statistical calculations were performed with SPSS (SPSS Inc., Chicago, IL), STATISTICA (StatSoft, Tulsa, $\mathrm{OK}$ ), and/or MedCalc (MedCalcSoftware, Mariakerke, Belgium) computer software.

\section{Results}

\section{Patient characteristcs}

In this study, a total of 700 patients (539 females, 161 males; initial age: $46.7 \pm 16.6 \mathrm{yrs}$ ) were followed up over a 20 year period. The initial age of patients ranged widely (18-88 years), and the mean age of study population was relatively young, with more than $50 \%$ being 
Table 1. Characteristics of symptomatic fracture and no symptomatic fracture groups of vertebrae at baseline and during the $\mathrm{GC}$ treatment

\begin{tabular}{|c|c|c|c|}
\hline & $\begin{array}{l}\text { Fracture } \\
\text { group }\end{array}$ & $\begin{array}{l}\text { No fracture } \\
\text { group }\end{array}$ & $\begin{array}{c}\text { Difference } \\
\text { P value }\end{array}$ \\
\hline Number of patients & 167 & 533 & \\
\hline Gender (female/male) & $133 / 34$ & $406 / 127$ & N.S. ${ }^{2)}$ \\
\hline Initial age (year) & $56.3 \pm 14.0$ & $43.6 \pm 16.3$ & $\mathrm{P}<0.001^{1)}$ \\
\hline BMI & $21.2 \pm 3.2$ & $21.5 \pm 3.2$ & N.S ${ }^{1)}$ \\
\hline Smoking $(\%)$ & $41(24.6 \%)$ & $134(25.1 \%)$ & N.S. ${ }^{2)}$ \\
\hline Alcohol use (\%) & $32(19.2 \%)$ & $94(17.6 \%)$ & N.S. ${ }^{2)}$ \\
\hline Initial dose of PSL (mg/day) & $39.0 \pm 14.8$ & $40.1 \pm 13.8$ & N.S. ${ }^{1)}$ \\
\hline Daily dose of PSL (mg/day) & $20.5 \pm 11.6$ & $13.2 \pm 6.4$ & $\mathrm{P}<0.001^{1)}$ \\
\hline Cumulative dose of PSL (g) & $24.5 \pm 21.5$ & $33.3 \pm 25.5$ & $\mathrm{P}<0.001^{1)}$ \\
\hline GC pulse therapy $(\%)$ & $25(15.0 \%)$ & $75(14.1 \%)$ & N.S. ${ }^{2)}$ \\
\hline Number of GC dose-increase $(0 / 1 / 2 / 3 / 4)$ & $73 / 64 / 21 / 6 / 3$ & $357 / 102 / 47 / 23 / 4$ & $\mathrm{P}<0.001^{1)}$ \\
\hline
\end{tabular}

Data are expressed as mean $\pm \mathrm{SD}$.

BMI, body mass index; PSL, prednisolone; GC, glucocorticoid

${ }^{1)}$ Unpaired t test, ${ }^{2)}$ Chi square test.

younger than age 50 . Among those, $77 \%$ was female, $18 \%$ used alcohol and $25 \%$ smoked initially.

About one third of the patients had systemic lupus erythematosus $(33.0 \%)$ as the underlying disease, and the rest of the patients had Sjogren's syndrome $(11.7 \%)$, polymyositis/dermatomyositis $(11.0 \%)$, rheumatoid arthritis $(9.6 \%)$, systemic sclerosis $(5.7 \%)$, mixed connective tissue disease $(5.1 \%)$, Wegener's granulomatosis $(0.9 \%)$, and others $(23.0 \%)$.

The initial GC dose was a high $39.9 \pm 14.1 \mathrm{mg} /$ day on average and the mean daily GC dose was $14.9 \pm 8.6$ $\mathrm{mg}$ /day (PSL equivalent). Among the patients, 38.6\% required dose-increase and $14.3 \%$ required GC pulse therapy during the study period. Cumulative GC dose was estimated to be $31.2 \pm 24.9 \mathrm{~g}$ (PSL equivalent) on average.

\section{Incidence of symptomatic vertebral fracture}

Among 700 patients, 167 patients (23.8\%) had at least one symptomatic vertebral fracture during the study period, indicating that incidence of symptomatic vertebral fracture was high. The fracture group had significantly higher mean age, higher daily dose, lower cumulative dose, and higher number of GC doseincrease in comparison to the no fracture group. No significant differences were observed between the two groups in gender, BMI, use of alcohol, smoking, initial GC dose and GC pulse therapy (Table 1).
When the patients were categorized into the groups with and without GC dose-increase, the two groups had similar BMI, use of alcohol, and smoking. However, the group with dose-increase had a higher percent of females, lower age, and higher initial dose, higher daily dose, higher cumulative dose, longer observation period, and higher rate of GC pulse therapy as shown in Table 2. According to the Kaplan-Meier analysis, the group with dose-increase had significantly lower no symptomatic vertebral fracture ratio in comparison to the group without dose-increase $(\mathrm{P}<0.05)$ as shown in Figure 1A. On the other hand, Kaplan-Meier analyses demonstrated that no significant differences were found between smoking and no smoking, and between alcohol use and no alcohol use as shown in Figures $1 \mathrm{~B}$ and $\mathrm{C}$.

\section{Risk factors for symptomatic vertebral fracture}

The risk factors of symptomatic vertebral fracture were evaluated with Cox regression models for gender, initial age, BMI, smoking, initial alcohol use, initial dose, cumulative dose, number of GC dose-increase, and GC pulse therapy, as shown in Table 3. The risk for symptomatic vertebral fracture was independently higher in female patients with hazard ratio (HR) $1.774(1.133-2.777,95 \% \mathrm{CI})$, in every 10 -year increment of the initial age with HR 1.787 (1.577$2.024,95 \% \mathrm{CI}$ ), in every $5 \mathrm{mg}$ /day of initial GC dose 
Table 2. Characteristics of patients with and without GC dose-increase at baseline and during GC treatment

\begin{tabular}{lccc}
\hline & $\begin{array}{c}\text { No dose-increase } \\
\text { group }\end{array}$ & $\begin{array}{c}\text { Dose-increase } \\
\text { group }\end{array}$ & $\begin{array}{c}\text { Difference } \\
\text { P value }\end{array}$ \\
\hline Number of patients & 430 & 270 & \\
Gender (female/male) & $320 / 110$ & $219 / 51$ & $\mathrm{p}<0.05^{2)}$ \\
Initial age (years) & $49.4 \pm 16.8$ & $42.3 \pm 15.5$ & $\mathrm{p}<0.001^{1)}$ \\
BMI & $21.5 \pm 3.3$ & $21.3 \pm 3.1$ & N.S. ${ }^{1)}$ \\
Smoking (\%) & $111(25.8 \%)$ & $64(23.7 \%)$ & N.S. ${ }^{2)}$ \\
Alcohol use (\%) & $72(16.7 \%)$ & $54(20.0 \%)$ & N.S. ${ }^{2)}$ \\
\hline Observation period (months) & $83.0 \pm 63.3$ & $134.7 \pm 72.9$ & $\mathrm{p}<0.001^{1)}$ \\
Initial dose of PSL (mg/day) & $38.0 \pm 12.5$ & $42.8 \pm 15.8$ & $\mathrm{p}<0.001^{1)}$ \\
Daily dose of PSL (mg/day) & $13.8 \pm 7.4$ & $16.8 \pm 9.8$ & $\mathrm{p}<0.001^{1)}$ \\
Cumulative dose of PSL (g) & $23.1 \pm 19.3$ & $44.1 \pm 27.2$ & $\mathrm{p}<0.001^{1)}$ \\
GC pulse therapy (\%) & $42(9.8 \%)$ & $58(21.5 \%)$ & $\mathrm{p}<0.001^{2)}$ \\
Vertebral fracture (\%) & $73(17.0 \%)$ & $94(34.8 \%)$ & $\mathrm{p}<0.001^{2)}$ \\
\hline
\end{tabular}

Data are expressed as mean $\pm \mathrm{SD}$.

BMI, body mass index; PSL, prednisolone; GC, glucocorticoid

${ }^{1)}$ Unpaired $t$ test, ${ }^{2)} \mathrm{Chi}$ square test

Table 3. Evaluation of risk factors for symptomatic vertebral fracture using Cox proportional hazard regression model

\begin{tabular}{lcc}
\hline Variables & $\begin{array}{c}\text { Hazard ratio } \\
(95 \% \text { confidence interval })\end{array}$ & P- values \\
\hline Female & $1.774(1.133-2.777)$ & $\mathrm{P}<0.05$ \\
BMI (every 1 BMI) & $0.981(0.933-1.031)$ & $\mathrm{N} . \mathrm{S}$. \\
Initial age (every 10 years) & $1.787(1.577-2.024)$ & $\mathrm{P}<0.001$ \\
Smoking & $1.353(0.889-2.059)$ & $\mathrm{N} . \mathrm{S}$. \\
Alcohol use & $1.083(0.660-1.777)$ & $\mathrm{N} . \mathrm{S}$. \\
Initial dose of PSL (ever 5mg/day) & $1.241(1.157-1.332)$ & $\mathrm{P}<0.001$ \\
Number of GC dose-increase & $2.457(2.054-2.939)$ & $\mathrm{P}<0.001$ \\
GC pulse therapy & $1.317(0.830-2.090)$ & $\mathrm{N} . \mathrm{S}$. \\
Cumulative dose of PSL (every 1g) & $0.922(0.908-0.935)$ & $\mathrm{P}<0.001$ \\
\hline
\end{tabular}

BMI, body mass index; PSL, prednisolone; GC; glucocorticoid.

Hazard ratio of risk factors was calculated using Cox proportional hazard regression model (confidence interval of $95 \%)$.

(prednisolone equivalent) with HR 1.241(1.157-1.332, $95 \% \mathrm{CI}$ ) and in every GC dose-increase with HR 2.457 $(2.054-2.939,95 \% \mathrm{CI})$. However, the symptomatic vertebral fracture risk was independently higher in decrease of every gram of cumulative GC dose (prednisolone equivalent) with HR 0.922 (0.908-0.935, 95\% $\mathrm{CI})$, indicating that GC dose increase, higher age, female, higher initial GC dose and lower cumulative GC dose were factors for fracture risk. In contrast, BMI, smoking, alcohol use and GC pulse therapy were not associated with vertebral fracture.

\section{Discussion}

In the present study, the prevalence of symptomatic vertebral fracture was high $(23.8 \%)$ in Japanese patients with collagen vascular diseases, and required the treatment of initial high dose of GC (more than $20 \mathrm{mg}$ PSL equivalent) daily. Risk factors for symptomatic vertebral fracture were found to be age, female, higher initial GC dose, and greater number of GC doseincrease. Lower cumulative GC dose was associated with the group with symptomatic vertebral fracture. 
A

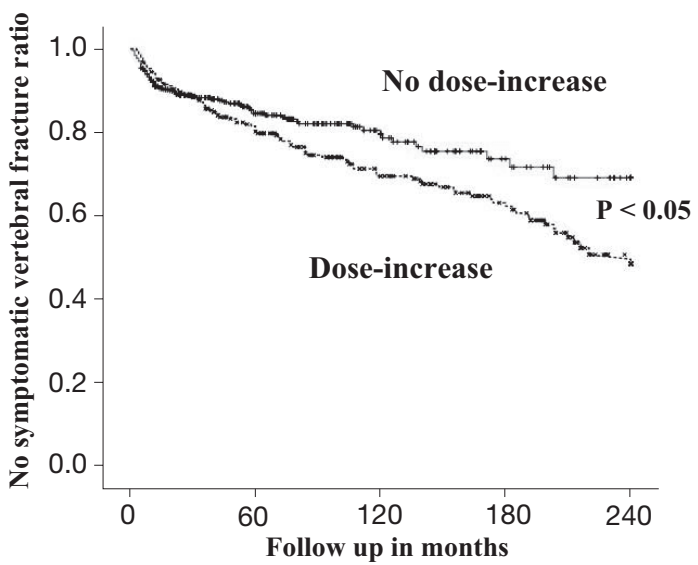

B

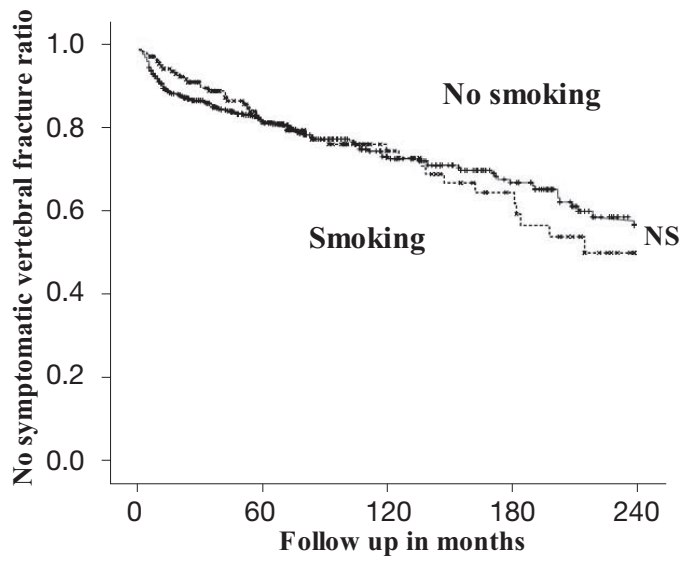

\begin{tabular}{llcccc} 
Cumulative Events & Dose-increase & 0 & 51 & 72 & 82 \\
\multirow{3}{*}{ No. at Risk } & No dose-increase & 0 & 58 & 66 & 71 \\
& Dose-increase & 270 & 183 & 116 & 76 \\
& No dose-increase & 430 & 201 & 85 & 37
\end{tabular}

$\begin{array}{llllll}\text { Cumulative Events Smoking } & 0 & 25 & 31 & 36\end{array}$

$\begin{array}{lllll}\text { No smoking } & 0 & 84 & 107 & 117\end{array}$

No. at Risk

$\begin{array}{lllll}\text { Smoking } & 175 \quad 90 & 46 & 25\end{array}$

$\begin{array}{lllll}\text { No smoking } \quad 525 & 294 & 155 & 88\end{array}$

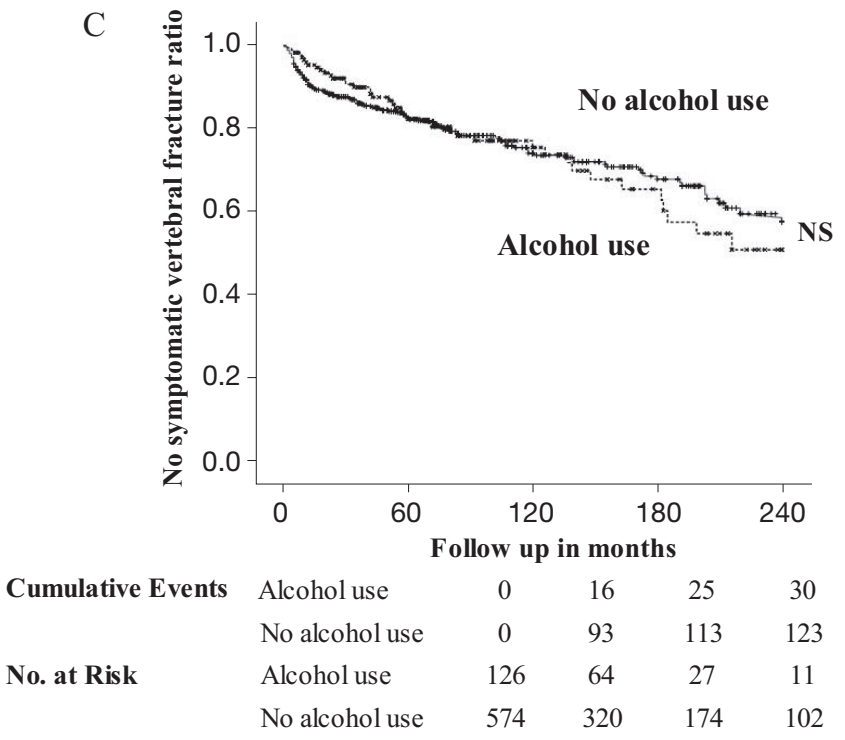

Fig. 1. Kaplan-Meier estimates of the no symptomatic vertebral fracture ratio in patients (A) with and without GC dose-increase, (B) between smoking and no smoking, and $(\mathrm{C})$ between alcohol use and no alcohol use.

The collagen vascular diseases are chronic and occasionally life-threatening, thus requiring long term high-dose GC treatment $[11,12,17,18]$. The mean initial daily dose $(39.9 \pm 14.1 \mathrm{mg} /$ day), daily doses (14.9 $\pm 8.5 \mathrm{mg} /$ day $)$ and cumulative dose $(31.2 \pm 25.0 \mathrm{~g})$ of the present study were approximately two times higher than those used in previous large population studies $[19,20]$. The doses and periods may be high enough to produce rapid damage to the bone structure. The incidence of symptomatic vertebral fracture was markedly higher (23.8\%) in the present study than the $12.3 \%$ and $9.1 \%$ found in the patients with systemic lupus erythematosus both in a large US population-based study of the 1994 National Health Interview Survey [13], and in the patients of a cross sectional study of a large UK cohort of patients with systemic lupus erythematosus [15], respectively.

Symptomatic vertebral fracture in our study occurred in both age- and female-dependent manners. However, the results of previous studies and the metaanalyses on risk factors for vertebral fractures involving GC treatment were controversial $[5,7,20,21]$. 
Naganathan et al. observed that the incidence of vertebral deformities was higher in GC users age 60 and older than the younger users [19]. On the other hand, Peel et al. observed the opposite results in a study of 76 postmenopausal women with steroid-treated rheumatoid arthritis (aged 50-79 years), where the vertebral deformity was most prevalent in the patients aged 50-59 years [22]. Recently, we also demonstrated the age-dependency of symptomatic vertebral fracture with high-dose GC treatment using the age quartiles in the sub-analysis of CSRC, in which the hazard ratio was 26-fold higher in patients aged 60-88 than in patients aged 18-31 years $(\mathrm{P}<0.01)$ [23]. In addition, symptomatic vertebral fractures occur within shorter period of GC treatment as patients' age increased [23].

The association between gender and fracture risk has also been debated. Female as well as duration of $\mathrm{GC}$ administration and age were associated with bone fractures in patients with rheumatoid arthritis according to the multivariate analyses [24], whereas no significant difference in GC-induced fracture risk was reported between male and female in some studies $[8,19]$ and meta-analysis $[20,21]$. The possible explanation for age- and gender-dependence of GC-induced fracture in the present study could be the style, design and size of study. GC-induced fracture in the previous large-scale studies were mostly examined in crosssectional and population-based manners [8,20,21,25$30]$. A majority of longitudinal studies on bone fracture were on small-scale and included relatively few new GC users [20]. The present study covered a large number of 700 new GC users with the mean age of a much younger and wider range [46.7 (18-88) years] compared with other studies. The present longitudinal study had one of the longest study periods, 20 years. We also reported the female-dependent risk of symptomatic vertebral fracture in the elderly in the subanalysis of CSRC [31].

Although the pathophysiological relevance in the relation between gender or age and GC-induced osteoporosis was not elucidated, the effect of GC on inhibition of bone formation appears to be more important than that on stimulation of bone resorption [3], and the direct effect on both osteoblastic lineage and osteocytes appears to be critical. GC is known to reduce the mature osteoblast pool, and to impair osteoblastic differentiation and maturation [3]. It is of therapeutic interest to note that teriparatide, which stimulates bone formation, was reported to reduce the risk of vertebral fractures in GC-induced osteoporosis [32]. Thus, the association of bone formation to our findings, age and gender dependence in fracture risk must be examined in the future.

The correlation between fracture risk and GC dose (accumulative or daily) is of clinical importance. In the present study, both the higher initial dose and the greater numbers of GC dose-increase were two independent risk factors. The increased fracture risk with intermittent high-dose oral GC therapy was recently demonstrated by others [33], indicating that the exposure to high GC dose during a long period of time might produce the bone damage. However, the very high GC dose with a short period of exposure may not be what induces the damage, since GC pulse therapy was not correlated to bone fracture.

Both the activity and type of underlying disease may influence the GC dose and the number of doseincrease, which in turn may affect the degree of bone damage. In previous studies, bone loss in inflammatory bowel disease, rheumatoid arthritis, and chronic obstructive pulmonary disease is reported to be independent of GC treatment [3, 7, 34-37]. The systemic release of inflammatory cytokines affect bone formation and bone resorption, and seems to underlie the pathophysiology of bone loss $[35,37]$. In these aspects, a subgroup analysis of the type and activity of diseases is necessary in the future.

We found an unexpected negative correlation between cumulative GC dose and fracture risk in the present study, whereas the positive correlations between cumulative dose and fracture risk were contrarily found in previous studies [38-40]. Especially, a strong relationship between daily dose and fracture risk and a weak correlation between cumulative dose and fracture risk were found in a large populationbased cohort study in UK [8]. Although it is difficult to determine the basis for the negative association in the present study, there are several possible explanations. 1. There may be some genetic or environmental risk factors in the vertebral fracture group, which may shorten the duration to produce vertebral fracture. As a result, the cumulative dose might be negatively associated with fracture risk. 2. GC might be masking the symptomatic vertebral fracture through the reduction of pain and causing the underestimation, since GC is used to control many types of acute pain including cancer $[41,42]$ by reducing local production of inflammatory cytokines. However, this explanation 
seems unlikely, since long-term GC administration is reported to have no effect on acute nociceptive thresholds in rats [43].

Our study has several limitations. Although the correlation between bone mineral density and GCinduced fracture risk has been discussed for years [21], we have no data on bone mineral density in the study subjects. Recent evidence has suggested that bone strength is determined by both bone mineral density and bone quality, and that bone quality may be more critical for GC-induced fracture risk than bone mineral density [21]. Recently, it has been known that vertebral fracture associated with GC therapy often is asymptomatic [3, 44, 45]. Since the clinical observation of the condition initiated the diagnostic procedure for symptomatic vertebral fracture in the present study, the fracture incidences observed might be less than the degree of actual occurrence.

The treatment of GC-induced osteoporosis has been extensively studied for the past several decades, and guidelines on the management and treatment of GCinduced osteoporosis have been published in Western countries and Japan $[46,47]$. In general, the management of patients exposed to GC includes general health measures, sufficient calcium, and vitamin D, and reducing the therapeutic regimen to the minimal effective dose [5]. The pharmacological treatment of GC-induced osteoporosis involves the use of bisphosphonates [5]. Our data may indicate the use of bisphosphonates should be considered soon after beginning GC therapy, especially with high-dose.

In conclusion, Japanese patients with collagen vascular diseases, who require long-term high-dose GC treatment, have a high risk of symptomatic vertebral fractures. Since the independent risk factors include female gender, initial age, high initial dose and high number of GC dose-increase, the methods of GC treatment, and the age- and gender-dependent bone strength of the patient may influence GC-induced osteoporosis.

\section{Acknowledgment}

We wish to acknowledge Drs. K. Suyama, A. Nagata, H. Hosaka, and A. Minezawa (Chiba University, Japan) for their valuable assistance. We also wish to thank Professor P. H. Stern (Northwestern University, USA) for valuable advice.

\section{References}

1. Cushing $\mathrm{H}$ (1932) The basophilic adenomas of the pituitary body and their clinical manifestations (pituitary basophilism). Bull Johns Hopkins Hosp 1:137-192.

2. Canalis E, Bilezikian JP, Angeli A, Giustina A (2004) Perspectives on glucocorticoid-induced osteoporosis. Bone 34:593-8.

3. Canalis E, Mazziotti G, Giustina A, Bilezikian JP (2007) Glucocorticoid-induced osteoporosis: pathophysiology and therapy. Osteoporos Int 18:1319-1328.

4. Manelli F, Giustina A (2000) Glucocorticoid-induced osteoporosis. Trends Endocrinol Metab 11:79-85.

5. Mazziotti G, Angeli A, Bilezikian JP, Canalis E, Giustina A (2006) Glucocorticoid-induced osteoporosis: an update. Trends Endocrinol Metab 17:144-9.

6. Shaker JL, Lukert BP (2005) Osteoporosis associated with excess glucocorticoids. Endocrinol Metab Clin North Am 34:341-56, viii-ix.

7. van Staa TP (2006) The pathogenesis, epidemiology and management of glucocorticoid-induced osteoporosis. Calcif Tissue Int 79:129-37.

8. Van Staa TP, Leufkens HG, Abenhaim L, Zhang B, Cooper C (2000) Use of oral corticosteroids and risk of fractures. J Bone Miner Res 15:993-1000.

9. Cervera R, Khamashta MA, Font J, Sebastiani GD, Gil A, Lavilla P, Mejia JC, Aydintug AO, ChwalinskaSadowska H, de Ramon E, Fernandez-Nebro A, Galeazzi M, Valen M, Mathieu A, Houssiau F, Caro N, Alba P, Ramos-Casals M, Ingelmo M, Hughes GR (2003) Morbidity and mortality in systemic lupus erythematosus during a 10-year period: a comparison of early and late manifestations in a cohort of 1,000 patients. Medicine (Baltimore) 82:299-308.

10. Jardinet D, Lefebvre C, Depresseux G, Lambert M, Devogelaer JP, Houssiau FA (2000) Longitudinal analysis of bone mineral density in pre-menopausal female systemic lupus erythematosus patients: deleterious role of glucocorticoid therapy at the lumbar spine. Rheumatology (Oxford) 39:389-92.

11. Langford CA (1997) Chronic immunosuppressive therapy for systemic vasculitis. Curr Opin Rheumatol 9:41-7.

12. Nagai S, Izumi T (1997) Immunopathology of collagen vascular disease. Curr Opin Pulm Med 3:356-60.

13. Ramsey-Goldman R, Dunn JE, Huang CF, Dunlop D, 
Rairie JE, Fitzgerald S, Manzi S (1999) Frequency of fractures in women with systemic lupus erythematosus: comparison with United States population data. Arthritis Rheum 42:882-90.

14. Sinigaglia L, Varenna M, Girasole G, Bianchi G (2006) Epidemiology of osteoporosis in rheumatic diseases. Rheum Dis Clin North Am 32:631-58.

15. Yee CS, Crabtree N, Skan J, Amft N, Bowman S, Situnayake D, Gordon C (2005) Prevalence and predictors of fragility fractures in systemic lupus erythematosus. Ann Rheum Dis 64:111-3.

16. Genant HK, Wu CY, van Kuijk C, Nevitt MC (1993) Vertebral fracture assessment using a semiquantitative technique. J Bone Miner Res 8:1137-48.

17. Chatham WW, Kimberly RP (2001) Treatment of lupus with corticosteroids. Lupus 10:140-7.

18. Parker BJ, Bruce IN (2007) High dose methylprednisolone therapy for the treatment of severe systemic lupus erythematosus. Lupus 16:387-93.

19. Naganathan V, Jones G, Nash P, Nicholson G, Eisman J, Sambrook PN (2000) Vertebral fracture risk with longterm corticosteroid therapy: prevalence and relation to age, bone density, and corticosteroid use. Arch Intern Med 160:2917-22.

20. van Staa TP, Leufkens HG, Cooper C (2002) The epidemiology of corticosteroid-induced osteoporosis: a meta-analysis. Osteoporos Int 13:777-87.

21. Kanis JA, Johansson H, Oden A, Johnell O, de Laet C, Melton IL, Tenenhouse A, Reeve J, Silman AJ, Pols HA, Eisman JA, McCloskey EV, Mellstrom D (2004) A meta-analysis of prior corticosteroid use and fracture risk. J Bone Miner Res 19:893-9.

22. Peel NF, Moore DJ, Barrington NA, Bax DE, Eastell R (1995) Risk of vertebral fracture and relationship to bone mineral density in steroid treated rheumatoid arthritis. Ann Rheum Dis 54:801-6.

23. Tatsuno I, Sugiyama T, Suzuki S, Yoshida T, Tanaka T, Sueishi M, Saito Y (2009) Age-dependent early complication of symptomatic vertebral fracture with highdose glucocorticoid in treatment for collagen vascular diseases. J Clin Endocrinol Metab (in press).

24. Michel BA, Bloch DA, Wolfe F, Fries JF (1993) Fractures in rheumatoid arthritis: an evaluation of associated risk factors. J Rheumatol 20:1666-9.

25. Adachi JD, Ioannidis G, Pickard L, Berger C, Prior JC, Joseph L, Hanley DA, Olszynski WP, Murray TM, Anastassiades T, Hopman W, Brown JP, Kirkland S, Joyce C, Papaioannou A, Poliquin S, Tenenhouse A, Papadimitropoulos EA (2003) The association between osteoporotic fractures and health-related quality of life as measured by the Health Utilities Index in the Canadian Multicentre Osteoporosis Study (CaMos). Osteoporos Int 14:895-904.

26. De Laet CE, Van Hout BA, Burger H, Weel AE, Hofman A, Pols HA (1998) Hip fracture prediction in elderly men and women: validation in the Rotterdam study. J Bone Miner Res 13:1587-93.

27. Johansson C, Black D, Johnell O, Oden A, Mellstrom D (1998) Bone mineral density is a predictor of survival. Calcif Tissue Int 63:190-6.

28. Jones G, Nguyen T, Sambrook PN, Kelly PJ, Gilbert C, Eisman JA (1994) Symptomatic fracture incidence in elderly men and women: the Dubbo Osteoporosis Epidemiology Study (DOES). Osteoporos Int 4:277-82.

29. Melton LJ, $3^{\text {rd }}$, Crowson CS, O'Fallon WM, Wahner HW, Riggs BL (2003) Relative contributions of bone density, bone turnover, and clinical risk factors to longterm fracture prediction. J Bone Miner Res 18:312-8.

30. O’Neill TW, Felsenberg D, Varlow J, Cooper C, Kanis JA, Silman AJ (1996) The prevalence of vertebral deformity in European men and women: the European Vertebral Osteoporosis Study. J Bone Miner Res 11:1010-8.

31. Tatsuno I, Suzuki S, Yoshida T, Tanaka T, Sueishi M, Sugiyama T (2009) High prevalence and early complication of symptomatic vertebral fracture in the elderly treated with high-dose glucocorticoids. J Am Geriatr Soc 57:188-9.

32. Saag KG, Shane E, Boonen S, Marin F, Donley DW, Taylor KA, Dalsky GP, Marcus R (2007) Teriparatide or alendronate in glucocorticoid-induced osteoporosis. N Engl J Med 357:2028-39.

33. De Vries F, Bracke M, Leufkens HG, Lammers JW, Cooper C, Van Staa TP (2007) Fracture risk with intermittent high-dose oral glucocorticoid therapy. Arthritis Rheum 56:208-14.

34. Lekamwasam S, Trivedi DP, Khaw KT (2002) An association between respiratory function and bone mineral density in women from the general community: a cross sectional study. Osteoporos Int 13:710-5.

35. Romas E (2005) Bone loss in inflammatory arthritis: mechanisms and therapeutic approaches with bisphosphonates. Best Pract Res Clin Rheumatol 19:1065-79.

36. Sin DD, Man JP, Man SF (2003) The risk of osteoporosis in Caucasian men and women with obstructive airways disease. Am J Med 114:10-4.

37. van Hogezand RA, Hamdy NA (2006) Skeletal morbidity in inflammatory bowel disease. Scand $J$ Gastroenterol Suppl 59-64.

38. Dykman TR, Gluck OS, Murphy WA, Hahn TJ, Hahn BH (1985) Evaluation of factors associated with glucocorticoid-induced osteopenia in patients with rheumatic diseases. Arthritis Rheum 28:361-8.

39. McEvoy CE, Ensrud KE, Bender E, Genant HK, Yu W, Griffith JM, Niewoehner DE (1998) Association between corticosteroid use and vertebral fractures in older men with chronic obstructive pulmonary disease. Am J Respir Crit Care Med 157:704-9.

40. Walsh LJ, Wong CA, Oborne J, Cooper S, Lewis SA, Pringle M, Hubbard R, Tattersfield AE (2001) Adverse 
effects of oral corticosteroids in relation to dose in patients with lung disease. Thorax 56:279-84.

41. Kingery WS (1997) A critical review of controlled clinical trials for peripheral neuropathic pain and complex regional pain syndromes. Pain 73:123-39.

42. Lussier D, Huskey AG, Portenoy RK (2004) Adjuvant analgesics in cancer pain management. Oncologist 9:571-91.

43. Kingery WS, Castellote JM, Maze M (1999) Methylprednisolone prevents the development of autotomy and neuropathic edema in rats, but has no effect on nociceptive thresholds. Pain 80:555-66.

44. Angeli A, Guglielmi G, Dovio A, Capelli G, de Feo D, Giannini S, Giorgino R, Moro L, Giustina A (2006) High prevalence of asymptomatic vertebral fractures in post-menopausal women receiving chronic glucocorticoid therapy: a cross-sectional outpatient study. Bone
39:253-9.

45. de Nijs RN, Jacobs JW, Lems WF, Laan RF, Algra A, Huisman AM, Buskens E, de Laet CE, Oostveen AC, Geusens PP, Bruyn GA, Dijkmans BA, Bijlsma JW (2006) Alendronate or alfacalcidol in glucocorticoidinduced osteoporosis. N Engl J Med 355:675-84.

46. Compston J (2004) US and UK guidelines for glucocorticoid-induced osteoporosis: similarities and differences. Curr Rheumatol Rep 6:66-9.

47. Nawata H, Soen S, Takayanagi R, Tanaka I, Takaoka K, Fukunaga M, Matsumoto T, Suzuki Y, Tanaka H, Fujiwara S, Miki T, Sagawa A, Nishizawa Y, Seino Y (2005) Guidelines on the management and treatment of glucocorticoid-induced osteoporosis of the Japanese Society for Bone and Mineral Research (2004). J Bone Miner Metab 23:105-9. 